\title{
COVID-crisis: opportunities vs challenges for innovative transformations and self-development
}

\author{
Galyna Piatnytska ${ }^{1 *}$, Oleh Hryhorenko ${ }^{2}$, and Valentyna Zhukovska ${ }^{1}$ \\ ${ }^{1}$ Kyiv National University of Trade \& Economics, Department of Management, 19 Kyoto str., 02156 \\ Kyiv, Ukraine \\ ${ }^{2}$ Kyiv National University of Trade \& Economics, Department of Design and Engineering, \\ 19 Kyoto str., 02156 Kyiv, Ukraine
}

\begin{abstract}
Topical issues related to the identification of factors influencing innovative transformations during the COVID-crisis have been highlighted. The aim of the study is to identify opportunities and challenges for innovative transformations and self-development in the context of the COVID-crisis. The methods of systems analysis, surveys and synthesis were used. Research data confirmed that the pandemic has not fundamentally changed the fact that the potential of breakthrough innovations continues to exist. It is not expedient for enterprises to abandon R\&D and innovations, despite the current challenges. Innovative transformations require not only financial support, but also human resources and innovative ideas. According to our survey of students in 2020, it was identified that today they can be divided into those who are: 1) able to develop and try to solve problems regardless of the situation; 2) able to take advantage of opportunities but may be unable to resist threats and solve problems; 3 ) unable to make constructive decisions and think creatively in the COVID-crisis. To ensure progressive innovation development, the number of the first group should be the largest, and the third - the smallest. It is concluded that currently, the situation for innovative transformations is ambiguous. The paradox of imaginary and real positioning is revealed. This showed discrepancies between how potential business managers assess opportunities and respond to challenges in the COVID-crisis.
\end{abstract}

\section{Introduction}

The crisis caused by the pandemic may change the nature of globalization and the structure of international business relations. It should be noted that such an unpredictable crisis as the COVID-crisis has led to the emergence and growth of a number of risks. These risks have certainly had a negative impact on business development in many sectors of the economy.

\footnotetext{
*Corresponding author: galx230167@gmail.com
} 
At the same time, like any other crisis, the COVID-crisis has become a specific driver of change and finding completely new ways to solve existing problems.

The measures enacted to contain the pandemic had a varied impact on economic activity across economic sectors and countries in 2020. The bans on public events, strict lockdowns and restrictions on numerous activities in the spring and summer of 2020 had a dramatic effect on the economy of the different countries around the world. Even today there is still significant uncertainty about the evolution of the pandemic, the containment measures and the associated economic effects.

\section{Literature review}

Crises are classified on various grounds: the possibility of forecasting, the degree of control, the adequacy of decision-making time in crisis management, the degree of influence on the functioning of management entities, reasons of occurrence, degree of systematization, temporal characteristics, sphere of origin, degree of influence, degree of influencing factors and others [1-5]. Crises on the scale of manifestation are divided into: general, i.e. those that cause various crises in the whole socio-economic system, and local [4]. COVID-crisis on this basis can clearly be attributed to general crises.

At the same time, recalling John F. Kennedy's famous speeches in 1959 and 1960, B. Zimmer [6] noted that the President associated the Chinese term "crisis" with two Chinese symbols (namely 危机), one of which he translated into English as "danger" and the other one as "opportunity". This associative translation is now widely used, but it is only partially correct because the second Chinese symbol actually has several meanings and means something more like "change point". Thus, any crisis actually means a situation where the change point has been reached and this may require certain (including probably innovative) transformations to overcome the danger.

Many years ago, J. Schumpeter [7] proved that innovation is the main source of economic growth. Since then, the importance of innovation for growth has not diminished. However, quite often in practice, the implementation of innovative ideas requires additional resources (including financial), which are difficult to find in an economic crisis. According to international experience, innovation and innovative transformations are needed not only in conditions of stable development for economic growth. They are useful, and sometimes extremely necessary, even in the conditions of crisis phenomena and their consequences. This is confirmed by studies of the different scientists [8-12].

It should be noted that the COVID-crisis is no exception and, like other crises, requires change. In particular, this is evidenced by effective innovation transformations in enterprises of various spheres of economic activity during the pandemic [13].

Recently, scientists have paid attention to the study of such issues as: critical evaluation of the system of investment assistance in the process of managing innovative development [14]; formation of a system for monitoring the level of financial and economic safety of the enterprise with taking into account innovative changes of functional, organizational, structural nature, as well as determining the benefits of innovative changes in the system of monitoring the enterprise based on a balanced scorecard [15]; development of a model of the procedure for supporting digital innovation transformations in small and medium-sized enterprises with the involvement of government support units [16]; development of innovation and investment projects to improve the efficiency of management systems [17], etc.

In our previous studies, the dichotomy of innovative transformations was identified [11]; the analysis of social innovations was carried out [18]; an assessment of the innovative potential of enterprises in various sectors of the economy during the deployment of the fourth wave of globalization was conducted [10]; the correlation between the new 
requirements for managers (in particular, HR-managers) of companies and the rapid development of digital innovative technologies that began to be actively used during the pandemic [19], etc.

It is well known that innovations and innovative transformations can be divided into: improving; radical; ordinary. Any innovative transformation allows an enterprise or company to get one or more effects at the same time. These are such effects as: scientific and technical; economic; social; ecological; integral.

Innovative transformations take place regardless of the opportunities and threats of the market environment. However, not every innovative change causes the desired results in the management of the enterprise in a pandemic [11]. This is due to the dual nature of the probable consequences of innovative transformations: on the one hand, they may lead to the emergence of new competitive advantages of the enterprise, and on the other - lead to its additional costs and risks.

Despite all the above research results, aspects of self-development during the COVIDcrisis have not yet been studied. The question of whether the pandemic situation has opened up new opportunities or whether it has only caused challenges for effective innovation transformations also needs further analysis. Therefore, the aim of our study is to identify opportunities and challenges for innovative transformations and self-development in the context of the COVID-crisis.

\section{Material and method}

Finding out the features of the COVID crisis, as well as identifying challenges and opportunities for innovative transformations in the pandemic situation and its limitations, is based on data analysis of the World Bank, International Monetary Fund, International Labor Organization, State Employment Center in Ukraine, etc. For this purpose, methods of statistical data processing, system analysis and synthesis were used.

An online survey was used to identify opportunities and challenges for selfdevelopment during the Covid-crisis. This issue was investigated by interviewing students of Ukrainian universities during the hard lockdown during April - May 2020.

The entire sample consisted of 1152 respondents (students from different courses, groups and universities of Ukraine). However, the most representative was the sample of student youth studying at different faculties of the Kyiv National University of Trade and Economics (KNUTE). 703 students from KNUTE answered the questionnaire (i.e. it is almost $2 \%$ of the total number of students who studying at this university).

\section{Results and discussion}

Determining the features of the COVID-crisis was carried out on the basis of analysis of various indicators. Thus, according to the results of the analysis of Global GDP growth per capita during periods of global downturn (Fig. 1), it was found that this crisis is due to the deepest global recession since World War II.

Another feature of the COVID-crisis is the high rate of spread and significant loss of working time (Fig. 2). The COVID crisis also prompted structural changes in the economies of many countries. These changes are related to the following characteristics:

- Growing share of services, especially electronic;

- Sectoral transformations due to long-term restrictions, prohibitions, social distancing that introduced for reasons of health; destruction or deformation of supply and marketing supply chains, closure of borders, government decision to close down enterprises that are not absolutely necessary for the basic provision of citizens; 
- Active dissemination of the practice of working remotely;

- Automation and use of AI because companies will continue to focus on reducing the use of human labor;

- Priority of the project format of work in comparison with full-time work;

- There is a high probability of strengthening the position and role of large companies and international corporations compared to SMEs (especially because some small entrepreneurs will be forced to leave the market);

- Awareness of the threats of a high level of dependence on other countries both in terms of supply and demand (especially if it could weaken independence in economic activities and life support).

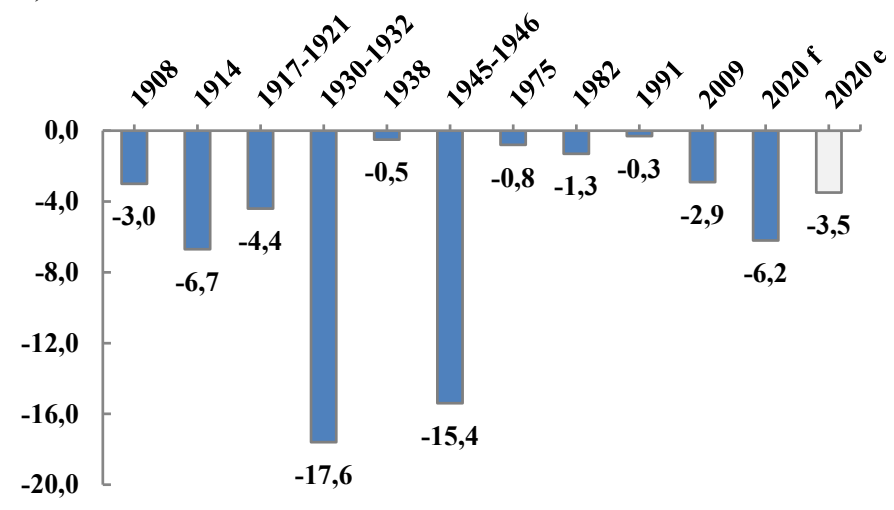

Fig. 1. Global GDP growth per capita during periods of global downturn, $\%$ *

Source: The diagram is constructed by the authors based on data from World Bank [20; 21] and Kose et al. [22].

Note. ${ }^{*}$ For perennial episodes, a cumulative reduction is shown. Data for $2020 \mathrm{f}$ is the forecast as of June 2020 \& Data for 2020 e is the estimated data as of June 2021.

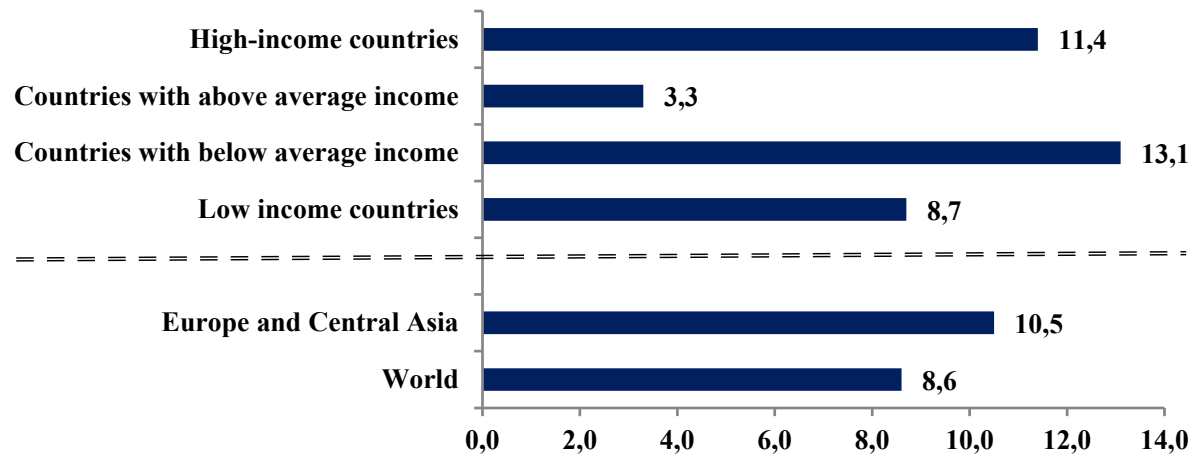

Fig. 2. Increasing the percentage of lost working time in the world and by income groups, in the second quarter compared to the first in $2020, \%$

Source: The author's calculations according to ILO Monitor: COVID-19 and the world of work, 2020 [23].

However, the most threatening feature of COVID-crisis is that such type of crisis lead to a growing gap between rich and poor. This, in particular, is confirmed by the fact that IMF experts estimate the impact of the pandemic on poverty according to five major similar 
events in the last 20 years - outbreaks of SARS (2003), H1N1 (2009), MERS (2012), Ebola 2014) and Zika (2016) [24].

It is clear that any changes (especially crisis) always affect the life of absolutely all subjects of market relations. Thus, it was established that one of the main challenges for employers during quarantine and the current crisis was the rapid need to transfer employees to remote operation activity. It is worth noting that changes to the possibility of remote working and flexible scheduling have recently been made to the Labor Code of Ukraine.

At the same time, managers of many enterprises and companies immediately felt that not every employee can perform their tasks at home due to lack of experience in remote work, lack of proper technical support, low level of information literacy of some employees. There are challenges related to the organization and implementation of control over the performance of both individual and team work of employees. The disadvantages of long-distance communication immediately manifested themselves in a decrease in the level of coherence in the work of individual teams of workers. And although this has become a new challenge for managers, at the same time this situation should be seen as new opportunities to find ways to improve existing and introduce new managerial methods.

Based on the results of the work of different companies during the COVID-crisis and the distinctive features of this crisis, let's identify the main challenges for innovative transformations in this period. The list of such challenges should include:

1. The challenge of insufficient investment to support the desired dynamics of innovative development;

2. The challenge of the need for further automation and digitization of business processes in various organizations (including universities);

3. The challenge of the lack of human resources which are able to generate innovative ideas and to make decisions;

4. The challenges of dependence on: a) supply chains of vital products from other countries under lockdown; b) structural orientation in industries that have entered to a decline stage of development during the crisis.

5. The challenges of poor cybersecurity.

However, along with the challenges, there are always opportunities. Among the general opportunities for innovative transformations in the COVID-crisis, the following should be emphasized:

- An opportunity to restart the economy (first of all, by operational investment in the restructuring of the economy in response to modern market challenges);

- Favorable conditions for starting a new business and become a leader if the entrepreneur has the resources (especially financial). From our point of view, there are two acceptable orientations for development: 1) focus on the frugal customer; 2) focus on a business that loses popularity during the crisis, but will probably recover after the crisis and will be profitable;

- High chances to hire highly qualified workers and buy the necessary materials at a lower price;

- Reducing the level of competition and, as a consequence, an opportunity to strengthen market position (for example, by improving access to potential consumers of innovative goods and services);

- New opportunities and the need to intensify digitalization of universities in response to the second of the underlined challenges.

The next step in our study was a survey of students of Ukrainian universities in the period from April to May 2020. The survey identified opportunities and challenges for selfdevelopment during the COVID-crisis. 1152 students answered the questionnaire, which has already been noted above. 
The results of the research found that slightly more than $55 \%$ of the surveyed respondents (students) personally perceived quarantine and the crisis as a challenge (Fig. 3). However, for only $2 / 5$ of them this challenge not only complicated life, but also led to confusion, misunderstanding and reluctance to do anything at all, while for the rest it was an impetus for active search for solutions to their problems, encouraged them to action and creative thinking.

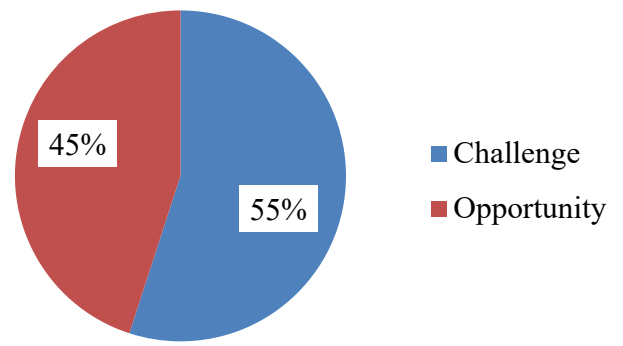

Fig. 3. Perception of COVID-crisis by student youth

Source: Developed by the author based on survey data.

Quite significant (approximately $45 \%$ ) is the share of those who immediately perceived quarantine and the crisis as new opportunities that enriched their experience of learning and / or working in conditions of unpredictable changes. But while almost $30 \%$ say that these opportunities have opened up new prospects for them personally to develop, build future careers and/or put creative ideas into practice, $15 \%$ say that along with opportunities, they have faced many challenges that hindered their development.

In general, if to look critically at the distribution of opinions of the respondents, there can be stated the presence of three groups in the student environment: 1) those who act, develop and try to solve problems, regardless of whether they face challenges or opportunities; 2) those who are able to assess and seize opportunities, but may be unable to resist threats and solve problems; 3 ) those who get lost and frightened in the face of new challenges, unable to make constructive decisions and think creatively in times of crisis. To ensure the progressive development of any country, in our opinion, it is very important that the number of the first group was the largest, and the third was the smallest (and not only when it comes to youth).

In a calm situation, far from a crisis, it is very difficult and time-consuming to determine how critical the mass of one or another of the above groups is in the country. However, during quarantine and crisis, this can be done quickly enough. In this case, the share of active youth who are able to act and solve problems regardless of the circumstances is more than $63 \%$, and those who are more likely to need help during the crisis is less than $22 \%$ (Fig. 4). Although it is usually desirable that it be even smaller.

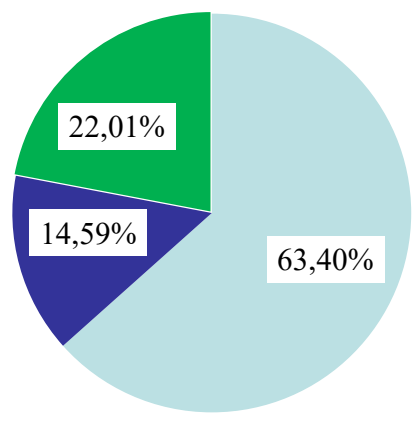

those who develop and try to solve problems
regardless of whether they face challenges or
opportunities

- those who see opportunities in the crisis, but may be unable to resist threats and solve problems

- those who get lost and frightened in the face of new challenges, unable to make constructive decisions and think creatively in times of crisis 
Fig. 4. Self-identification of student-respondents during the COVID-crisis

Source: Developed by the author based on survey data.

At the same time, as it turned out, quarantine and the current crisis nevertheless provided students with a number of opportunities that most of them were able to take advantage of. In the questionnaire, we were asked to choose up to five options from 11 alternatives or provide their own answer. The majority of students $(55,5 \%$ of the total number of respondents) emphasized that the main thing for them was the opportunity to learn something new, to acquire a new skill, for which there was not enough time before. In addition to this opportunity, the top five alternatives also include: "Start paying more attention to learning and self-development" $(51,7 \%)$; "Learn to better communicate and interact with their relatives and friends" (46,5\%); "Get experience online" (40,0\%); "Learn something completely new about what didn't even think before" $(31,3 \%)$. At the same time, about $17 \%$ have the opportunity to develop a project to create a new business; in more than $16 \%$ - the opportunity to expand the network of their acquaintances and communication contacts. About $9 \%$ had the opportunity to start doing scientific or research findings, developing interesting ideas that can bring economic, social and other effects, etc. It is worth noting that among all respondents, less than $0,5 \%$ did not see, and therefore did not use any opportunities.

The above percentages are evidence of the paradox between how a person positions himself / herself in a given situation (in this case - during quarantine and crisis) and how he / she feels and actually acts in real life. Recall that $22 \%$ of young people at the beginning of the survey did not see any opportunities for themselves in the current situation and positioned themselves as confused and unwilling or unable to do anything, but in fact, there were less than one percent. Such declining attitudes among young, intelligent and physically strong people can only be partly explained by the fact that, unfortunately, today they see challenges that hinder both the growth of the country in which they live and them personally.

In the course of the research, it was found that the vast majority of young people surveyed see quarantine and the current crisis as new challenges than new opportunities for Ukraine. Unfortunately, almost half of the respondents do not see any opportunities for our country in this situation and about $1 / 4$ of the respondents could not answer or said that it is difficult for them to identify any opportunities. At the same time, identifying the main challenges facing Ukraine as a result of quarantine and crisis, among the 16 alternative answers and the opportunity to write their own, the vast majority (over $85 \%$ ) chose the decline in small and medium business (SME). In addition to the problems with the development of SMEs, the top five threats to the leaders also include the following: "Unsatisfactory provision and problems in the organization of the medical system in the country" ( $60,8 \%$ of the total number of respondents); "Speculative price increase" $(56,9 \%)$; "Complete unpreparedness of the population (especially the elderly) to use online communication in everyday life" $(51,0 \%)$; "Lack of a clear strategy for overcoming the crisis and determining further prospects for Ukraine's development" $(50,6 \%)$.

$43,1 \%$ of respondents also identified the rapid growth of social insecurity as the main challenge for Ukraine, and $34,1 \%$ identified disadvantages or poor technical and information support for the organization of quality remote work or training. Challenges such as: corruption and selective legal liability for violating the law during the quarantine period (30,0 \% of respondents) also received a significant number of votes; falling volumes of foreign trade in goods and services $(26,9 \%$ ); unprofessionalism in the work of local authorities $(23,8 \%)$. Almost $1 / 5$ of the respondents named as the current main challenges for Ukraine: the existence of the practice to lobby the interests and state support of exclusively large business and oligarchic families; unprofessionalism in the work of the 
Verkhovna Rada and its decisions that harm the national interests of Ukraine; imperfection of Ukrainian legislation, standards and norms. So, there are a lot of challenges and, as it can seen, some of them appeared long before the quarantine and the crisis caused by it.

\section{Conclusions}

Thus, the COVID-crisis has not only created new challenges, but also opened up new opportunities for innovative change. Those who passively do not wait for the situation to stabilize, and are already doing everything for progressive innovative transformations, will gain a competitive advantage in the strategic perspective.

The pandemic has not fundamentally changed the fact that the potential of breakthrough innovations continues to exist. However, effective innovation transformations always require resources and intellectual capital.

The COVID-crisis has a number of special characteristics. The innovative transformations during this crisis require not only financial support, but also human resources and innovative ideas. According to our survey, the students (and with them the population of the country as a whole) can divided into those who are: 1) able to develop and try to solve problems regardless of the situation; 2) able to take advantage of opportunities but may be unable to resist threats and solve problems; 3) unable to make constructive decisions and think creatively in the COVID-crisis. To ensure progressive innovation development, the number of the first group should be the largest, and the third - the smallest. This should apply to absolutely all age groups of the economically active population in the country.

Currently the situation for innovative transformations in Ukraine and some other countries is ambiguous. However, this does not mean that these ambitions will be realized in practice.

It is established that the correct positioning at the change point plays an important role. The paradox of imaginary and real positioning is revealed. This showed discrepancies between how potential business managers assess opportunities and respond to challenges in the COVID-crisis.

\section{References}

1. J.J. Lee, J.P. Haupt, HE 81, 949-966 (2021)

2. M. Sreenivasulu, M. Sridevi, PCS 167, 962-968 (2020)

3. A.S. Claeys, V. Cauberghe, JBR 67(2), 182-189 (2014)

4. P.V. Kuhta, Kryzy, ih prychyny ta naslidky (Crises, their caused and consequences), Efektyvna ekonomika 10 (2012), http://www.economy.nayka.com.ua/?op=1\&z=1439, [Accessed: 2 June 2021]

5. I. Fedulova, G. Piatnytska, Ekonomika ta derzhava 8, 26-34 (2020)

6. B. Zimmer, Crisis = danger + opportunity: The plot thickens. Language Log, 27 March 2007, http://itre.cis.upenn.edu/ myl/languagelog/archives/004343.html, [Accessed: 10 June 2021]

7. J.A. Schumpeter, The Theory of Economic Development, Transaction Publishers, New Brunswick, New Jersey (2008)

8. V. Heyets, M. Skrypnychenko, S. Shumska, FCAPTP, 2(33), 296-305 (2020),

9. V.M. Zhukovska, SMEU, 1(2), 10-17 (2019)

10. I. Fedulova, G. Piatnytska, L. Lukashova, MMI 3, 216-228 (2018)

11. G. Piatnytska, O. Hryhorenko, T. Dolzhenko, ZTEFP, 2(115), 30-43 (2021)

12. K. Laursen, B. Leten, N. H. Nguyen, M. Vancauteren, RP, 49(9) (2020) 
13. G.T. Piatnytska et al., Fundamental and applied research in the modern world, Abstracts of the 6th International scientific and practical conference (BoScience Publisher, Boston, 2127, 2021)

14. L. Hvolkova, L. Klement, MMI 1, 26-39 (2020)

15. H.B. Svinarova, Economic journal Odessa polytechnic university 4(10), 123-128 (2019)

16. B. Barann, A. Hermann, Ann-K. Cordes, Fr. Chasin, J. Becker, Supporting Digital Transformation in Small and Medium-sized Enterprises: A Procedure Model Involving Publicly Funded Support Units, in Proceedings of the 52nd Hawaii International Conference on System Sciences, (HICSS), 8-11 January 2019, Granf Wailea, Maui, (2019)

17. A. Kasych, Investytsiyi: praktyka ta dosvid, 13, 81-85 (2020)

18. V.M. Zhukovska, Sotsialnyi rozvytok orhanizatsii: potentsial, upravlinnya, innovatsii, (Kyiv: KNUTE), (2018)

19. V. Zhukovska, G. Piatnytska, N. Raksha, L. Lukashova, O. Salimon, HR-manager: Prospects for Employment in the Labor Markets, in Proceedings of $3^{\text {rd }}$ EECME $2021-$ Sustainable Development in Modern Knowledge Society, 28 May 2021: SHS Web of Conf. 111, Ljubljana, Slovenia

20. World Bank. Global Economic Prospects, (Washington, DC: World Bank, (2020)

21. World Bank. Global Economic Prospects, (Washington, DC: World Bank, 2021)

22. M.A. Kose, N. Sugawara, M.E. Terrones, Global recessions (CAMA Working Papers 2020-10, Centre for Applied Macroeconomic Analysis, Crawford School of Public Policy, The Australian National University), (2020)

23. International Labour Organization, ILO Monitor: COVID-19 and the world of work. Seventh edition Updated estimates and analysis, (2021), https://www.ilo.org/wcmsp5/groups/public/---dgreports/--dcomm/documents/briefingnote/wcms 767028.pdf, [Accessed: 10 June 2021]

24. D. Furceri, P. Loungani, J.D. Ostry, P.Pizzuto, The Rise in Inequality after Pandemics: Can Fiscal Support Play a Mitigating Role? (IMF, April 30, 2021), https:/www.imf.org/en/Publications/WP/Issues/2021/04/30/The-Rise-in-Inequality-afterPandemics-Can-Fiscal-Support-Play-a-Mitigating-Role-50287, [Accessed: 10 June 2021] 